(W)

updates

Cite as

Nano-Micro Lett.

(2020) 12:123

Received: 19 March 2020

Accepted: 9 May 2020

Published online: 9 June 2020

(C) The Author(s) 2020

\section{Confining $\mathrm{TiO}_{2}$ Nanotubes in PECVD-Enabled Graphene Capsules Toward Ultrafast K-Ion Storage: In Situ TEM/XRD Study and DFT Analysis}

\author{
Jingsheng Cai ${ }^{1}$, Ran $\mathrm{Cai}^{2}$, Zhongti Sun ${ }^{1}$, Xiangguo Wang ${ }^{1}$, Nan $\mathrm{Wei}^{1,3}, \mathrm{Feng} \mathrm{Xu}^{2}{ }^{凶}$, \\ Yuanlong Shao ${ }^{1,3}$, Peng Gao ${ }^{3,4}$, Shixue Dou ${ }^{5}$, Jingyu Sun ${ }^{1,3} \bowtie$ \\ Jingsheng Cai, Ran Cai and Zhongti Sun have contributed equally to this work. \\ $\bowtie$ Feng Xu, fxu@seu.edu.cn; Peng Gao, p-gao@pku.edu.cn; Jingyu Sun, sunjy86@ suda.edu.cn \\ 1 College of Energy, Soochow Institute for Energy and Materials InnovationS (SIEMIS), Key Laboratory \\ of Advanced Carbon Materials and Wearable Energy Technologies of Jiangsu Province, Soochow \\ University, Suzhou 215006, Jiangsu, People's Republic of China \\ 2 SEU-FEI Nano-Pico Center, Key Laboratory of MEMS of Ministry of Education, Southeast University, \\ Nanjing 210096, People's Republic of China \\ Beijing Graphene Institute (BGI), Beijing 100095, People's Republic of China \\ 4 Electron Microscopy Laboratory, International Centre for Quantum Materials, School of Physics, Peking \\ University, Beijing 100871, People's Republic of China \\ 5 Institute for Superconducting and Electronic Materials, University of Wollongong, Wollongong, NSW 2522, \\ Australia
}

\title{
HIGHLIGHTS
}

- $\mathrm{G}_{-} \mathrm{TiO}_{2}$ was fabricated via direct $\mathrm{CVD}$ route by growing few-layered graphene capsules over $\mathrm{TiO}_{2}$ nanotubes.

- K-ion hybrid capacitors based on the $\mathrm{G}-\mathrm{TiO}_{2}$ anode and $\mathrm{AC}$ cathode synergized high energy and high power density.

\begin{abstract}
Titanium dioxide $\left(\mathrm{TiO}_{2}\right)$ has gained burgeoning attention for potassium-ion storage because of its large theoretical capacity, wide availability, and environmental benignity. Nevertheless, the inherently poor conductivity gives rise to its sluggish reaction kinetics and inferior rate capability. Here, we report the direct graphene growth over $\mathrm{TiO}_{2}$ nanotubes by virtue of chemical vapor deposition. Such conformal graphene coatings effectively enhance the conductive environment and well accommodate the volume change of $\mathrm{TiO}_{2}$ upon potassiation/depotassiation. When paired with an activated carbon cathode, the graphene-armored $\mathrm{TiO}_{2}$ nanotubes allow the potassium-ion hybrid capacitor full cells to harvest an energy/ power density of $81.2 \mathrm{Wh} \mathrm{kg}^{-1} / 3746.6 \mathrm{~W} \mathrm{~kg}^{-1}$. We further employ in situ transmission electron microscopy and operando X-ray diffraction to probe the potassium-ion storage behavior. This work offers a viable and versatile solution to the anode design and in situ probing of potassium storage technologies that is readily promising for practical applications.
\end{abstract}

KEYWORDS $\mathrm{TiO}_{2}$; Potassium storage; In situ TEM; Plasma-enhanced CVD; Graphene

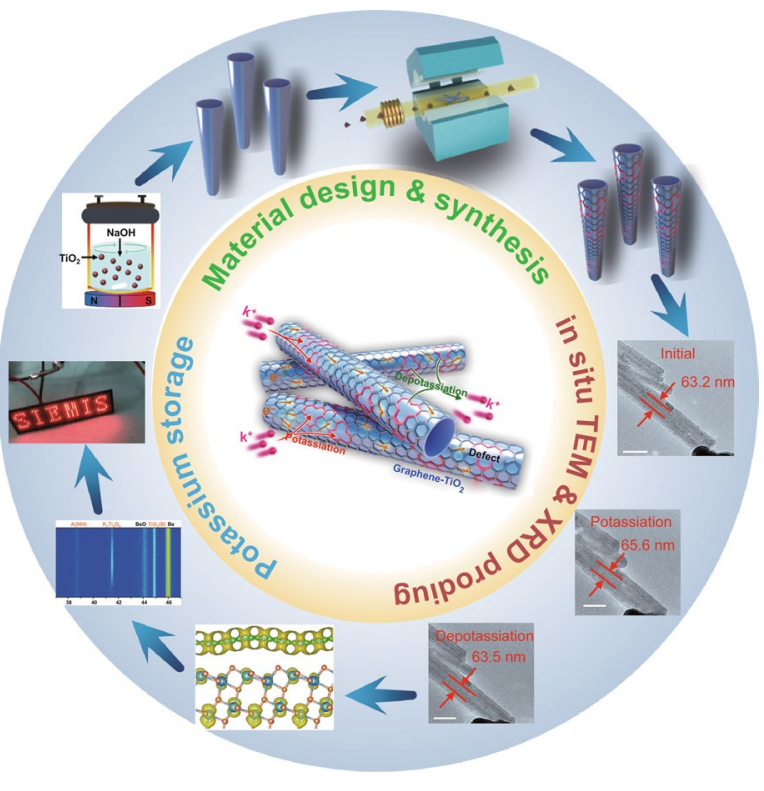




\section{Introduction}

Eco-friendly and sustainable energy storage systems play a vital role in the development of human society [1]. Despite the successful commercialization of lithium-ion batteries, the deficiency and uneven distribution of lithium resources nevertheless render it impractical to meet the ever-growing requirements of large-scale energy storage [2,3]. Recently, alternative metal-ion batteries (such as sodium and potassium) have stimulated massive attentions, owing to their similar electrochemistry to lithium, earth abundance (2.36, 2.09 , and $0.0017 \mathrm{wt} \%$ in the earth's crust for $\mathrm{Na}, \mathrm{K}$, and $\mathrm{Li}$, respectively), and cost-effectiveness $[4,5]$. In particular, potassium exhibits a lower standard redox potential $(-2.936 \mathrm{~V}$ vs. standard hydrogen electrode) than that of $\mathrm{Na}$ $(-2.714 \mathrm{~V})$, expecting a higher operating voltage window and an advanced energy density for potassium-ion batteries (KIBs) [6]. However, these merits have been plagued by the sluggish reaction kinetics during the (de)potassiation of large-sized $\mathrm{K}$ ions $\left[1.38 \AA\right.$, higher than $\mathrm{Na}^{+}(1.02 \AA)$ and $\left.\mathrm{Li}^{+}(0.76 \AA)\right]$ at the anode side [7]. As such, nanostructured design of electrode materials with open frameworks and/or topological defects is promising for the construction of highperformance potassium-ion-based energy storage systems, including KIBs and potassium-ion hybrid capacitors (KICs).

Titanium dioxide $\left(\mathrm{TiO}_{2}\right)$ has been probed as a feasible anode candidate in alkali metal-ion batteries because of the high theoretical capacity, broad availability, and environmental benignity [8-11]. Among versatile $\mathrm{TiO}_{2}$ nanostructures, one-dimensional $\mathrm{TiO}_{2}$ nanotube has gained wide attentions, which provides facile ion transport pathways and ensures adequate electrode-electrolyte contact [12, 13]. However, the intrinsic conductivity of $\mathrm{TiO}_{2}$ poses a daunting threat to the rate performance especially under high current densities, thereby resulting in an inferior potassium-ion storage [14]. To tackle this concern, a prevailing approach lies in the synergy of $\mathrm{TiO}_{2}$ with conductive media, such as carbonaceous materials, to efficiently boost the conductivity of $\mathrm{TiO}_{2}$-based anodes. For instance, the construction of $\mathrm{TiO}_{2}$-carbon heterostructure via a wet-chemical method was realized for advanced potassium-ion storage, relying upon a carbon content up to $28.1 \mathrm{wt} \%$ [13]. Nevertheless, it remains challenging by far to build a close contact between $\mathrm{TiO}_{2}$ and conducting carbon; hence, particle agglomeration and/ or volume expansion still occurs during the (de)potassiation process, giving rise to shortened cycle life. The ineffective interface of $\mathrm{TiO}_{2}$ and carbon might in addition impede the transport path of $\mathrm{K}$ ions to the surface of $\mathrm{TiO}_{2}$, thereby handicapping the pseudocapacitive contribution from $\mathrm{TiO}_{2}$. The high dosage of carbon would also undermine the energy density of resulting KIBs $[15,16]$. Meanwhile, detailed reaction process in terms of (de)potassiation and morphology evolution upon $\mathrm{K}^{+}$-ion uptake/release of $\mathrm{TiO}_{2}$ anode is still relatively poorly understood.

Herein, we report an in situ synthetic design of graphenearmored $\mathrm{TiO}_{2}$ nanotubes $\left(\mathrm{G}-\mathrm{TiO}_{2} \mathrm{NTs}\right)$ with pseudocapacitive potassium storage as reliable anode material for KIBs. The as-obtained $\mathrm{G}_{-} \mathrm{TiO}_{2}$ composite was fabricated via the direct growth of graphene on $\mathrm{TiO}_{2}$ NTs with the aid of plasma-enhanced chemical vapor deposition (PECVD) in a facile and scalable fashion. The unique architecture of $\mathrm{G}^{-\mathrm{TiO}_{2}} \mathrm{NTs}_{\mathrm{N}}$ possesses several major advantages: (1) the robust and intimate contact established between graphene and $\mathrm{TiO}_{2}$ affords outstanding electrical conductivity, which aids the capacity utilization of $\mathrm{TiO}_{2}$ cores; (2) the PECVD procedure allows the creation of topological defects within graphene overlayers, in turn helping easy permeation of electrolyte and facile intercalation of $\mathrm{K}$ ions; and (3) the armored graphene shells enable the effective cushion of volume change during the insertion/extraction of $\mathrm{K}$ ions, thereby improving the structural and electrochemical stability. As expected, thus-derived G-TiO $\mathrm{NTs}_{2}$ manifest excellent pseudocapacitive potassium storage performance with a high reversible capacity of $332 \mathrm{mAh} \mathrm{g}^{-1}$ at $0.05 \mathrm{~A} \mathrm{~g}^{-1}$ and an ultrastable high-rate cyclic stability (a capacity fading of $0.008 \%$ per cycle at $5 \mathrm{~A} \mathrm{~g}^{-1}$ for 3000 cycles), outperforming the state-of-the-art Ti-based counterparts. The potassium storage behavior pertaining to the $\mathrm{G}^{-\mathrm{TiO}_{2}}$ NTs is systematically probed throughout in situ transmission electron microscopy and operando X-ray diffraction, in combination with first-principle calculations. Furthermore, as a proof-ofconcept demonstration, a KIC full cell constructed with an activated carbon cathode and a $\mathrm{G}-\mathrm{TiO}_{2} \mathrm{NT}$ anode displays a high output voltage of $\sim 3 \mathrm{~V}$ and favorable energy density/ power density of $81.2 \mathrm{Wh} \mathrm{kg}^{-1} / 3747 \mathrm{~W} \mathrm{~kg}^{-1}$, suggesting the potential for practical applications. 


\section{Experimental}

\subsection{Synthesis of $\mathrm{TiO}_{2} \mathrm{NTs}$}

Briefly, $0.2 \mathrm{~g}$ of commercial $\mathrm{TiO}_{2}$ powder $(\mathrm{P} 25)$ and $30 \mathrm{~mL}$ of $\mathrm{NaOH}$ solution $(10 \mathrm{M})$ were added into a Teflon-lined autoclave $(50 \mathrm{~mL})$. The autoclave was then transferred into an oil bath and heated at $130{ }^{\circ} \mathrm{C}$ for $24 \mathrm{~h}$ accompanied by a continuous magnetic stirring. After cooling down to room temperature, a white jelly-like suspension was obtained, which was subsequently rinsed with deionized water for several times to reach a $\mathrm{pH}$ value of 7 . Finally, $\mathrm{TiO}_{2} \mathrm{NTs}$ were produced after dipping the precipitate in $0.1 \mathrm{M} \mathrm{HNO}_{3}$ solution for $24 \mathrm{~h}$ to displace sodium ions, followed by annealing in air at $450{ }^{\circ} \mathrm{C}$ for $3 \mathrm{~h}$.

\subsection{Direct PECVD Production of $\mathrm{G}_{-\mathrm{TiO}}$ NTs}

Thus-prepared $\mathrm{TiO}_{2}$ NTs were served as the growth substrate and evenly placed into a CVD tube furnace. The system was pumped to a base pressure of $0.1 \mathrm{~Pa}$ and then purged with highly purified Ar to remove the air. The furnace was afterward heated to $500{ }^{\circ} \mathrm{C}$ under an Ar atmosphere. A mixture of $\mathrm{Ar}(50 \mathrm{sccm})$ and $\mathrm{CH}_{4}(10 \mathrm{sccm})$ was introduced with the presence of plasma $(80 \mathrm{~W})$ to trigger the reaction and maintained for 40 min to obtain the final products $\mathrm{G}-\mathrm{TiO}_{2} \mathrm{NTs}$.

\subsection{Characterizations}

The morphologies of the samples were determined by scanning electron microscopy (SEM, Hitachi, SU-8010) and transmission electron microscopy (TEM, FEI, Tecnai G2 F20, 80-300 kV) equipped with an energy-dispersive $\mathrm{X}$-ray spectroscopy (EDS). The structures of the samples were characterized by X-ray diffraction (XRD) employing an X-ray diffractometer (D8 Advance, Bruker Inc., $40 \mathrm{kV}$, $40 \mathrm{~mA}$, a nickel-filtered $\mathrm{Cu} \mathrm{K} \alpha$ radiation) and Raman spectroscopy (Horiba Jobin-Yvon, LabRAM HR800). XPS measurements were taken using a Physical Electronics spectrometer (Quantera II, ULVAC-PHI, Inc.) with an Al K $\alpha$ source $(1486.7 \mathrm{eV})$ to probe the chemical composition. The carbon content of $\mathrm{G}_{-} \mathrm{TiO}_{2}$ NTs was quantitatively determined with the aid of a thermogravimetry analyzer (METTLER TOLEDO TGA/DSC1). The conductivity of the samples was measured by using a four-probe resistance measuring system (Guangzhou 4-probe Tech Co. Ltd., RTS-4).

\subsection{Electrochemical Measurements}

As for KIB half-cells, the working electrode slurry contained active materials (bare $\mathrm{TiO}_{2} \mathrm{NTs}$ or $\mathrm{G}-\mathrm{TiO}_{2} \mathrm{NTs}$ ), sodium alginate (Aldrich), and carbon black (Timcal, Switzerland) in Milli-Q water with a weight ratio of 7:1:2 onto a current collector of copper foils (purity 99.999\%; thickness $10 \mu \mathrm{m}$ ). Circular electrodes with a diameter of $13 \mathrm{~mm}$ were obtained using a punch machine and vacuum-dried at $120^{\circ} \mathrm{C}$ for $12 \mathrm{~h}$. The average loading mass of electrode was ca. $1.0 \mathrm{mg} \mathrm{cm}^{-2}$. The potassium foil, glass fiber, and a homogenous $0.8 \mathrm{M}$ $\mathrm{KPF}_{6}$ solution in ethylene carbonate/dimethyl carbonate (1:1 in volume) were selected as the counter electrode, separator, and electrolyte, respectively. The electrochemical performances were tested on CR2032-type coin cells assembled in an argon-filled glove box with oxygen and water below $0.01 \mathrm{ppm}$. Galvanostatic discharge/charge cycles were achieved by using the LAND CT2001A battery testing system (Wuhan, China) with a voltage range of $0.01-3.0 \mathrm{~V}$ (vs $\mathrm{K}^{+} / \mathrm{K}$ ) at room temperature. $\mathrm{CV}$ measurements at different scan rates and EIS between 1000 and $0.01 \mathrm{~Hz}$ were taken on an Autolab potentiostat (Autolab Instruments, Netherland). As for KIC full cells, CR 2032-type coin cells were constructed with $\mathrm{G}_{-\mathrm{TiO}}$ NTs as the anode and PAC as the cathode (weight ratio 1:4). For the fabrication of cathodes, $\mathrm{NaOH}$ solution with a certain concentration was used as the pore-forming agent to etch the commercial activated carbon to derive PAC. The PAC electrode was prepared by casting slurries of PAC, polyvinylidene fluoride, and conductive black carbon in N-methyl-2-pyrrolidone (NMP) with a weight ratio of 9:0.5:0.5 onto 15- $\mu \mathrm{m}$-thick aluminum foils (99.999\%). With respect to pre-activation, a KIB was assembled beforehand using $\mathrm{G}_{-1 i O}$ NTs as the working electrode, which was charged/discharged for 3 cycles at $0.03 \mathrm{~A} \mathrm{~g}^{-1}$. The gravimetric energy and power densities of the KIC device were calculated by numerically integrating the galvanostatic discharge profiles using Eq. 1:

$$
\begin{array}{r}
E_{\text {mass }}=\int_{t_{1}}^{t_{2}} I U / m \mathrm{~d} t \\
P_{\text {mass }}=E_{\text {mass }} / t
\end{array}
$$


where $I$ is the charge/discharge current, $U$ is the working voltage, $t_{1}$ and $t_{2}$ are the start/end-of-discharge time (s), respectively, and $t$ corresponds to the discharge time.

\subsection{DFT Simulations}

First-principle method based on DFT was used to reveal the conductivity of $\mathrm{G}_{-}-\mathrm{TiO}_{2} \mathrm{NTs}$, as implemented by Vienna ab initio simulation package (VASP) [17] software with the projector augmented wave pseudopotential (PAW) [18] to tackle the core and valence electron interactions. The exchange-correlation interactions are handled by generalized gradient approximation (GGA) functional parameterized by Perdew, Burke, and Ernzerhof (PBE) [19]. DFT-D3 method [20] is applied to correct the van der Waals interactions between graphene and $\mathrm{TiO}_{2}$ in the $\mathrm{G}-\mathrm{TiO}_{2}$ composites. The kinetic energy cutoff with the plane wave basis set is $400 \mathrm{eV}$, and the $k$ mesh of $3 \times 4 \times 1$ and $5 \times 8 \times 1$ sampling is used to the first Brillouin zone integration for geometric optimization and static calculations, respectively. The convergence criterion of total energy and force per atom are less than $10^{-5} \mathrm{eV}$ and $-0.02 \mathrm{eV} \AA^{-1}$, respectively. The model about $\mathrm{G}-\mathrm{TiO}_{2}$ composite interface is referring to the previous work using $5 \times 3$ supercell graphene to match $2 \times 2$ supercell $\mathrm{TiO}_{2}$ (101) surface with an angle of $\sim 110^{\circ}[21]$.

\section{Results and Discussion}

As depicted in Fig. 1a, G-TiO 2 NTs are prepared via a sequential two-step route [22] in a scalable manner. In the first step, commercial $\mathrm{TiO}_{2}$ powder (P25) (Fig. S1) and a tailored hydrothermal reaction are employed to produce one-dimensional $\mathrm{TiO}_{2}$ tubular nanostructures (Fig. S2). Subsequently, as-obtained $\mathrm{TiO}_{2}$ NTs are subject to a direct PECVD process using methane as the carbon precursor (Fig. S3), where defective graphene is in situ formed on the NT surface at a relatively low growth temperature (i.e., $500{ }^{\circ} \mathrm{C}$ ). The graphene coating generated by such a vapor-phase reaction is of high uniformity, evidenced by the obvious color change from bare white of $\mathrm{TiO}_{2}$ powders into dark gray of $\mathrm{G}_{-} \mathrm{TiO}_{2}$ in macroscopic quantity (Fig. S4). Compared with the routine graphene (such as reduced graphene oxide) [23] incorporation possessing ineffective contact toward active components for KIBs, the conformal caging of defective graphene overlayers can not only facilitate the electron transport and $\mathrm{K}$-ion diffusion, but also confine the $\mathrm{TiO}_{2}$ cores to accommodate the volume change that may occur upon charging/discharging (Fig. 1b). This would ultimately be beneficial to improving the rate capability and cycling stability.

Representative SEM image of thus-fabricated $\mathrm{TiO}_{2}$ exhibits an interwound nanotube morphology, with over $10 \mu \mathrm{m}$ in length and $20 \mathrm{~nm}$ in average width (Fig. S5). The structure of $\mathrm{TiO}_{2}$ can be well maintained after the PECVD process (Fig. 1c), indicative of mild reaction conditions for direct graphene wrapping to derive $\mathrm{G}-\mathrm{TiO}_{2}$. This is verified by TEM examination, readily showing uniform tubular morphologies of $\mathrm{G}_{-} \mathrm{TiO}_{2}$ (Fig. S6). High-resolution TEM (HRTEM) image in Fig. 1d reveals that the intact root of graphene onto the $\mathrm{TiO}_{2} \mathrm{NT}$ via direct CVD technique. It shows the lattice spacings of the (101) and (004) facets of the anatase phase and the (001) facet of the $\mathrm{TiO}_{2}(\mathrm{~B})$ phase, indicative of a dual-phase configuration, which is promising for the insertion/extraction of the alkali metal ions [12, 24]. Scanning transmission electron microscopy (STEM) image and corresponding elemental mappings (Fig. 1e) show the homogeneous distributions of $\mathrm{Ti}, \mathrm{O}$, and $\mathrm{C}$ elements, further confirming the uniform caging of graphene in situ to construct $\mathrm{G}-\mathrm{TiO}_{2}$ composite. Figure 1f displays the Raman spectrum of as-prepared $\mathrm{G}-\mathrm{TiO}_{2} \mathrm{NTs}$. The conspicuous signals at $143,396,515$, and $639 \mathrm{~cm}^{-1}$ are features of $\mathrm{TiO}_{2}$ [25]. It also manifests typical graphene signals, which encompasses a D band $\left(1345 \mathrm{~cm}^{-1}\right)$ attributed to the disordered carbon and a $\mathrm{G}$ band $\left(1590 \mathrm{~cm}^{-1}\right)$ attributed to the $s p^{2}$ carbon structure [26]. The $I_{\mathrm{D}} / I_{\mathrm{G}}$ ratio is greater than 1 , implying the existence of ample defects within the direct-PECVD-derived graphene overlayers, which can facilitate the ion diffusion to enhance the reaction kinetics [27]. $\mathrm{N}_{2}$ adsorption/desorption measurements suggest that PECVD-derived $\mathrm{G}_{-} \mathrm{TiO}_{2}$ NTs possesses a specific surface area of $52.0 \mathrm{~m}^{2} \mathrm{~g}^{-1}$ (Fig. $\mathrm{S} 7)$, which is higher than the pure $\mathrm{TiO}_{2}$ NTs $\left(45.1 \mathrm{~m}^{2} \mathrm{~g}^{-1}\right)$. The larger surface area and defect-rich graphene of $\mathrm{G}-\mathrm{TiO}_{2}$ NTs is beneficial to enriching the electron and ion pathways for advancing energy storage applications [15]. The content of graphene caging in the $\mathrm{G}-\mathrm{TiO}_{2}$ composite was determined to be $<5 \mathrm{wt} \%$ by thermogravimetric analysis, according to the weight loss observed from 100 to $780{ }^{\circ} \mathrm{C}$ (Fig. S8). Figure $1 \mathrm{~g}$ exhibits XRD data of $\mathrm{TiO}_{2}$ and $\mathrm{G}-\mathrm{TiO}_{2}$ NTs. Both samples show mixed phases of $\mathrm{TiO}_{2}$, namely bronze (B) (PDF\#46-1237) and anatase (A) (PDF\#02-0406). Note that bronze (B) $\mathrm{TiO}_{2}$ is suggested to be more favorable for the 
(a)

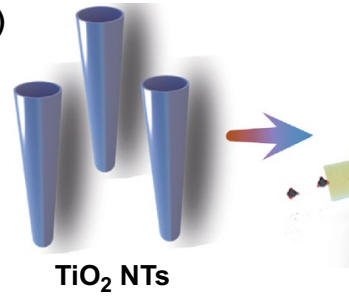

(c)

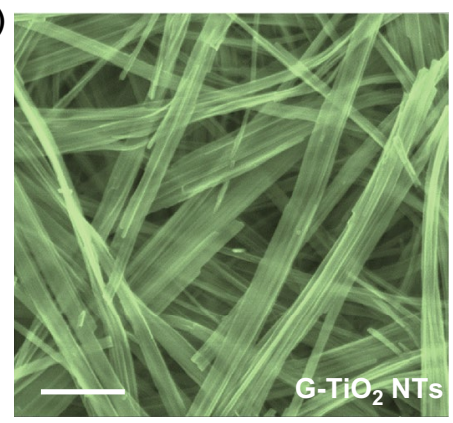

(f)

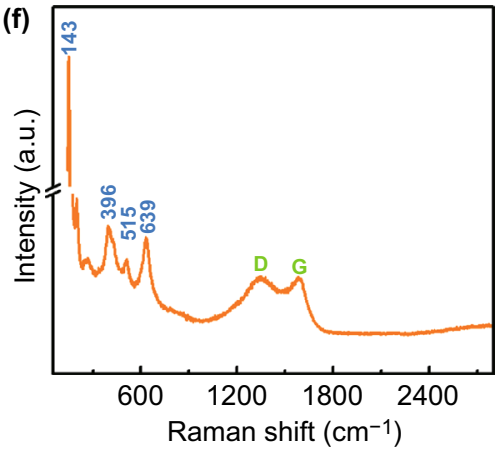

(d)

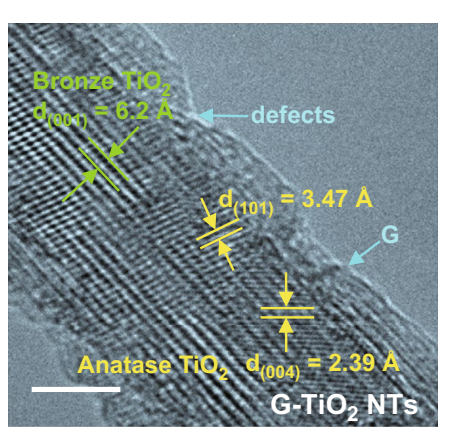

(g)

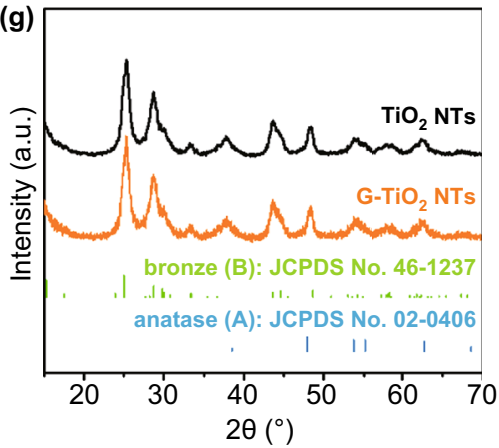

(b)

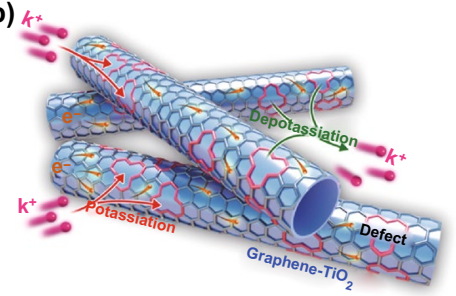

(e)
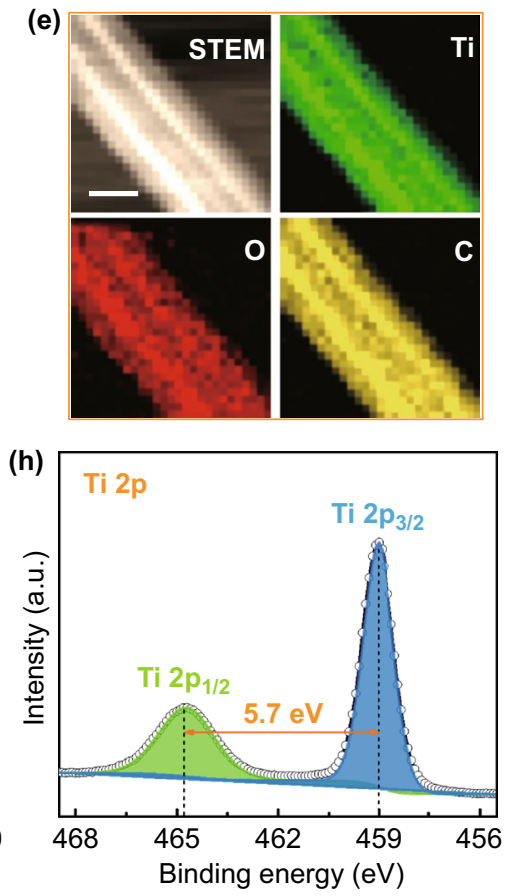

Fig. 1 Synthesis and characterization of G-TiO ${ }_{2}$ NTs. a Schematic illustration of the direct PECVD synthesis of G-TiO 2 NTs. b A schematic

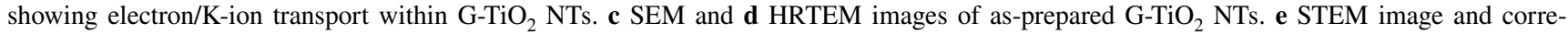
sponding elemental maps of G-TiO 2 NTs. $\mathbf{f}$ Raman spectrum of G-TiO ${ }_{2}$ NTs. $g$ XRD patterns of bare $\mathrm{TiO}_{2} \mathrm{NT}_{\mathrm{T}}$ and the PECVD-derived G-TiO 2 NTs. h XPS high-resolution Ti 2p spectrum of G-TiO ${ }_{2}$ NTs. Scale bars: c $500 \mathrm{~nm} ; \mathbf{d} 5 \mathrm{~nm}$; $50 \mathrm{~nm}$

intercalation of alkali metal ions [12], thus expecting an advanced potassium storage. To gain further insights into the chemical constitution of $\mathrm{G}_{-} \mathrm{TiO}_{2}$ NTs, XPS measurements were taken. The survey XPS data disclose the co-existence of Ti, O, and C elements (Fig. S9a). C 1 s high-resolution spectrum is contributed by a sharp $s p^{2} \mathrm{C}=\mathrm{C}$ peak as well as broad $\mathrm{C}-\mathrm{O}$ and $\mathrm{C}=\mathrm{O}$ peaks, indicating the formation of defective graphene by the PECVD method (Fig. S9b). O $1 \mathrm{~s}$ high-resolution spectrum (Fig. S9c) can be deconvoluted into two components, which are attributed to the $\mathrm{Ti}-\mathrm{O}-\mathrm{Ti}$ bonding in $\mathrm{TiO}_{2}$ and oxygen-containing functional groups on the surface of graphene (C-O), respectively [28]. Figure $1 \mathrm{~h}$ presents Ti $2 \mathrm{p}$ high-resolution XPS profile. The fitting peaks at $464.7\left(\mathrm{Ti} 2 \mathrm{p}_{1 / 2}\right)$ and $459.0 \mathrm{eV}\left(\mathrm{Ti} 2 \mathrm{p}_{3 / 2}\right)$ displays a binding energy gap of $5.7 \mathrm{eV}$, well suggesting the survival of $\mathrm{Ti}^{4+}$ in $\mathrm{G}^{-\mathrm{TiO}_{2}}$ NTs experiencing the PECVD process [29-31]. Upon direct graphene growth, the electrical conductivity of hybrids affords marked enhancement based on a sheet resistance mapping result (Fig. S10), showing an electrical conductivity value of $4.15 \mathrm{~S} \mathrm{~m}^{-1}$ [32].

Thus-designed G-TiO ${ }_{2}$ NTs were accordingly explored as anode materials to evaluate the potassium-ion storage performance, with bare $\mathrm{TiO}_{2}$ NTs serving as the control. Cyclic voltammetry $(\mathrm{CV})$ of the $\mathrm{G}-\mathrm{TiO}_{2}$ anode at a scan rate of $0.1 \mathrm{mV} \mathrm{s}^{-1}$ for the initial three cycles is shown (Fig. S11). Obviously, the first cathodic scan shows discernible peaks that deal with the decomposition of the electrolyte and the formation of solid electrolyte interphase (SEI) film [33]. The CV profiles overlap quite well at the second and third cycles, indicative of good reversibility. Further, the charge/ 
discharge curves of $\mathrm{G}_{-} \mathrm{TiO}_{2}$ NTs for the first cycle at different current densities are shown in Fig. 2a. The initial discharge and charge capacities at $0.05 \mathrm{~A} \mathrm{~g}^{-1}$ are 831 and $320 \mathrm{mAh} \mathrm{g}^{-1}$, respectively, with a quite low Coulombic efficiency. The large irreversible capacity can also be attributed to the formation of SEI layer during the potassiation process [33]. The following cycles at higher current densities witness stabilized charge/discharge profiles, implying a good reversibility after the initial activation and SEI film formation [16]. Figure $2 b$ compares the rate performances of bare $\mathrm{TiO}_{2}$ and $\mathrm{G}-\mathrm{TiO}_{2}$ NT electrodes at various charge/discharge rates. Augmenting the current density in a step-wise manner from 0.05 to $5 \mathrm{~A} \mathrm{~g}^{-1}$, the $\mathrm{G}_{-} \mathrm{TiO}_{2}$ NTs deliver a capacity of $271.6,258.7$,
217.3, 189.3, 166.8, 133.4, and $129.2 \mathrm{mAh} \mathrm{g}^{-1}$ at the rate of $0.05,0.1,0.2,0.5,1,2$, and $5 \mathrm{~A} \mathrm{~g}^{-1}$, respectively. When the rate returns to $0.05 \mathrm{~A} \mathrm{~g}^{-1}$, the $\mathrm{G}_{-} \mathrm{TiO}_{2} \mathrm{NTs}$ can still retain a capacity of $245.6 \mathrm{mAh} \mathrm{g}^{-1}$, exhibiting strong tolerance for fast potassiation/depotassiation and favorable reversibility. In contrast, the control $\mathrm{TiO}_{2}$ NTs without graphene caging and the heat-treated $\mathrm{TiO}_{2} \mathrm{NTs}$ [34] only harvest a low capacity of 75 and $120 \mathrm{mAh} \mathrm{g}^{-1}$ at $2 \mathrm{~A} \mathrm{~g}^{-1}$, respectively. Additionally, they deliver inferior capacities at a higher rate (i.e., $5 \mathrm{~A} \mathrm{~g}^{-1}$ ) (Fig. S12). The reversible capacity and Coulombic efficiency of the $\mathrm{G}_{-}-\mathrm{TiO}_{2}$ NTs at $0.1 \mathrm{~A} \mathrm{~g}^{-1}$ over 400 cycles are displayed in Fig. 2c. As such, a stable specific capacity of $222 \mathrm{mAh} \mathrm{g}^{-1}$ can still be retained after 400 cycles accompanying a high
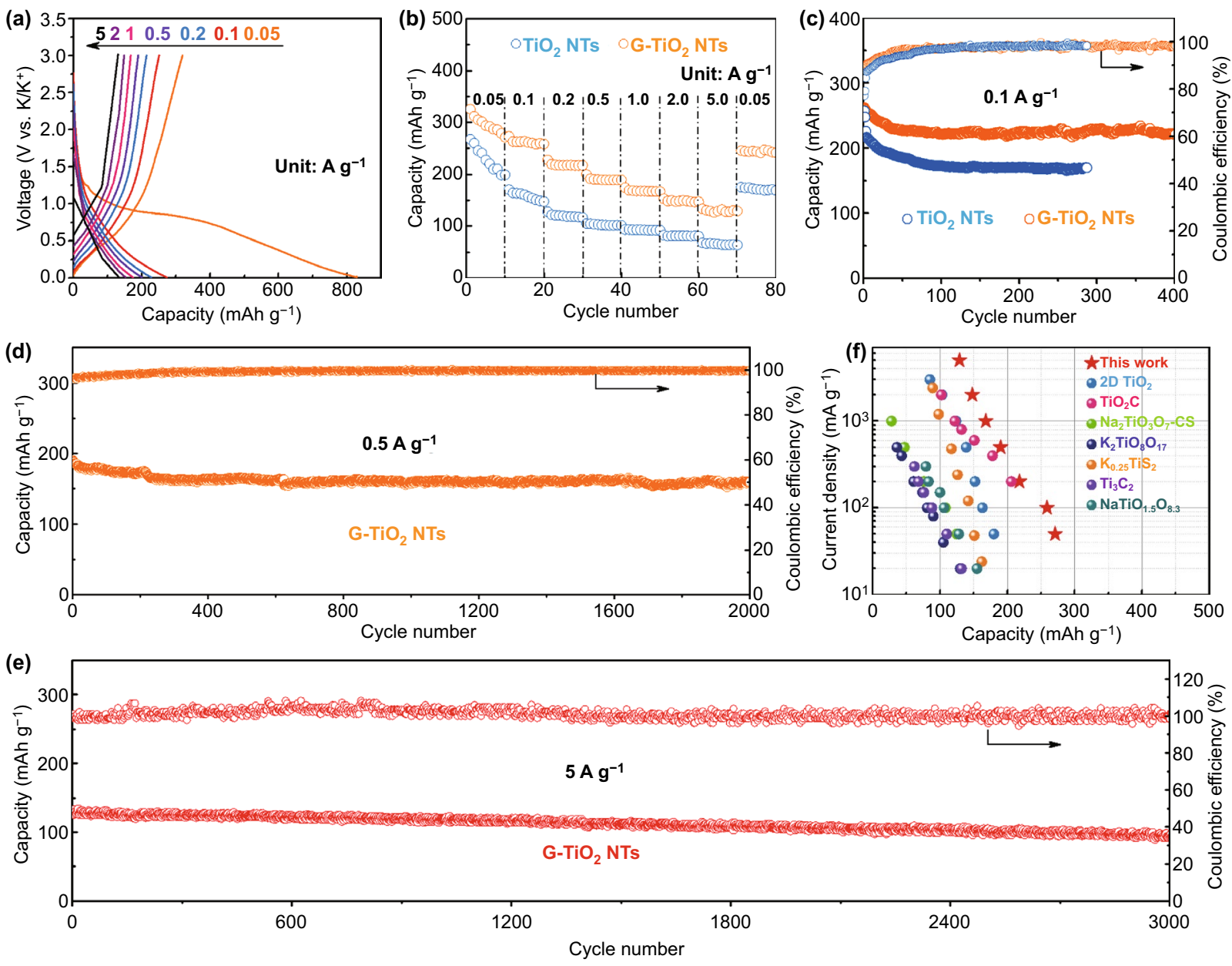

Fig. 2 Electrochemical performances of bare $\mathrm{TiO}_{2}$ NTs and $\mathrm{G}_{-\mathrm{TiO}}$ NTs as anodes in KIBs. a Galvanostatic charge-discharge profiles of G-TiO 2 NTs at various current densities of $0.05-5 \mathrm{~A} \mathrm{~g}^{-1}$. b Rate performances of bare $\mathrm{TiO}_{2} \mathrm{NTs}$ and $\mathrm{G}_{-} \mathrm{TiO}_{2}$ NTs at various current densities of 0.05-5 $\mathrm{A} \mathrm{g} \mathrm{g}^{-1}$. c Cycling performances of bare $\mathrm{TiO}_{2} \mathrm{NTs}$ and $\mathrm{G}-\mathrm{TiO}_{2} \mathrm{NTs}$ at a current density of $0.1 \mathrm{~A} \mathrm{~g}^{-1}$. d Cycling performance of G-TiO NTs at a current density of $0.5 \mathrm{~A} \mathrm{~g}^{-1}$ for 2000 cycles. e Cycling performance of G-TiO ${ }_{2}$ NTs at a current density of $5 \mathrm{~A} \mathrm{~g}^{-1}$ for 3000 cycles. f Comparison of the rate performances between our $\mathrm{G}_{-} \mathrm{TiO}_{2} \mathrm{NT}$ anode and the state-of-the-art Ti-based KIB anodes 
capacity retention of $84.1 \%$, which is evidently superior to that of bare $\mathrm{TiO}_{2} \mathrm{NT}$ anode (remaining $170 \mathrm{mAh} \mathrm{g}^{-1}$ after 300 cycles). As displayed in Fig. 2d, G-TiO ${ }_{2}$ electrode further exhibits an excellent cyclic stability at $0.5 \mathrm{~A} \mathrm{~g}^{-1}$, affording a reversible capacity of $160 \mathrm{mAh} \mathrm{g}^{-1}$ after 2000 cycles, which displays a higher capacity and stability as compared to those of other counterparts with different graphene dosages ( 3\% and $\sim 8 \%$ ) (Fig. S13). More significantly, after cycling at a high current density of $5 \mathrm{~A} \mathrm{~g}^{-1}$ for 3000 cycles, the $\mathrm{G}^{-\mathrm{TiO}_{2}}$ still delivers a capacity of $96 \mathrm{mAh} \mathrm{g}^{-1}$ with an extremely low capacity fading of $0.008 \%$ per cycle (Fig. 2e), manifesting ultrastable potassium storage capability. To the best of our knowledge, this is the first time that a Ti-based KIB anode with such a stable cycling performance at high rates has been demonstrated. Furthermore, performance comparisons with recent work on Ti-based anodes in KIBs are shown in Fig. $2 f$ [35-39]. Our work shows as one of the best results reported to date (Table S1).

Electrochemical impedance spectroscopy (EIS) was performed to demonstrate a lower charge-transfer resistance and higher K-ion diffusion kinetics of $\mathrm{G}_{-} \mathrm{TiO}_{2}$ NTs as compared to the control $\mathrm{TiO}_{2}$ NTs (Fig. S14), which can be ascribed to the enhanced electronic/ionic conductivity from the intimate graphene $/ \mathrm{TiO}_{2}$ interface. Galvanostatic intermittent titration technique (GITT) measurements (via discharging at $80 \mathrm{~mA} \mathrm{~g}^{-1}$ for $20 \mathrm{~min}$, followed by an open-circuit relaxation for $30 \mathrm{~min}$ ) were applied to analyze the $\mathrm{K}^{+}$diffusion coefficient $\left(\mathrm{D}_{\mathrm{K}}^{+}\right)$in bare $\mathrm{TiO}_{2}$ NTs and G-TiO ${ }_{2}$ NTs based on Eq. 2 [40]:

$D_{K^{+}}=\frac{4 L^{2}}{\pi \tau}\left(\frac{\Delta E_{\mathrm{s}}}{\Delta E_{\mathrm{t}}}\right)^{2}$

where $t$ is the duration time of the current pulse (s), $\tau$ is the relaxation time (s), $\Delta E_{\mathrm{s}}$ and $\Delta E_{\mathrm{t}}$ are the steady-state potential change $(\mathrm{V})$ by the current pulse and the potential change $(\mathrm{V})$ during the constant pulse after eliminating the $i R$ drop, respectively, and $L$ is the $\mathrm{K}^{+}$diffusion length (cm). In turn, our results show that the calculated diffusion coefficient $\left(\mathrm{D}_{\mathrm{K}}^{+}\right)$of $\mathrm{G}-\mathrm{TiO}_{2}$ NTs (between $7.59 \times 10^{-10}$ and $\left.3.88 \times 10^{-11} \mathrm{~cm}^{2} \mathrm{~s}^{-1}\right)$ is obviously higher than that of $\mathrm{TiO}_{2}$ NTs (between $3.74 \times 10^{-10}$ and $4.99 \times 10^{-12} \mathrm{~cm}^{2} \mathrm{~s}^{-1}$ ) upon discharge (Fig. S15), further corroborating advanced $\mathrm{K}^{+}$diffusion kinetics in $\mathrm{G}_{-} \mathrm{TiO}_{2}$ electrodes. The $\mathrm{K}^{+}$diffusion properties of both anodes were further explored by cyclic voltammetry (CV) at different scan rates of 0.1 to $2.0 \mathrm{mV} \mathrm{s}^{-1}$ (Fig. S16). The peak currents display a linear relationship with the square root of scan rates, in this respect, the classical
Randles-Sevcik equation (Eq. 3) [41] can be applied to quantify the ion diffusion process:

$i=\left(2.69 \times 10^{5}\right) \cdot n^{1.5} \cdot A \cdot D^{0.5} \cdot C_{K} \cdot v^{0.5}$

where $i, n, A, D, C$, and $v$ represent the peak current, chargetransfer number, area of the electrode, K-ion diffusion coefficient, concentration of $\mathrm{K}$ ions in the cathode, and the scan rate, respectively. In our case, $\mathrm{G}_{-} \mathrm{TiO}_{2} \mathrm{NTs}$ manifest advanced ion diffusion kinetics than that of $\mathrm{TiO}_{2} \mathrm{NTs}$ (Fig. S17). All these electrochemical characterizations corroborate the merits of $\mathrm{G}_{-} \mathrm{TiO}_{2}$ NTs with respect to ultrastable potassium storage performance at high rates and facile electron/K-ion transport.

To further probe the durability of G-TiO ${ }_{2}$ NTs with respect to potassium-ion storage, their structural evolutions during (de)potassiation cycles were examined by in situ TEM. The all-solid nanosized KIBs that enabled the real-time observation of in situ electrochemical experiments of $\mathrm{G}^{-\mathrm{TiO}_{2}} \mathrm{NTs}$ were constructed, as depicted in Fig. S18. Figure 3a-d presents the time-lapsed TEM images of different potassiation stages for $\mathrm{G}_{-} \mathrm{TiO}_{2}$ NTs collected during the first potassiation process (Movie S1). Prior to potassiation, the examined $\mathrm{G}^{-\mathrm{TiO}_{2}}$ NTs have an original diameter of $\sim 63.2 \mathrm{~nm}$. When a potential of $-2 \mathrm{~V}$ was applied to the $\mathrm{G}^{-\mathrm{TiO}_{2}} \mathrm{NTs}$ with respect to $\mathrm{K}$ electrode, potassium ions began to diffuse along the longitudinal direction starting from the point of contact with the $\mathrm{K} / \mathrm{K}_{2} \mathrm{O}$ layer. Such a potassiation process can be visualized by the increased diameter of $\mathrm{G}^{-\mathrm{TiO}_{2}}$ NTs to $64.6 \mathrm{~nm}$ at $20 \mathrm{~s}$ (Fig. 3b), resulting in the radial expansion as low as $2.2 \%$. With more potassium insertion, the $\mathrm{G}^{-\mathrm{TiO}_{2}}$ NTs continue to potassiation and finally acquire radial expansion of $3.7 \%$ after full potassiation (Fig. 3c, d), indicating that $\mathrm{K}$ storage in $\mathrm{G}^{-\mathrm{TiO}_{2}} \mathrm{NTs}_{\mathrm{N}}$ almost reaches its maximum capacity. No visible crack and fracture could be observed in the fully potassiated $\mathrm{G}^{-\mathrm{TiO}_{2}} \mathrm{NTs}$, suggesting a reliable structural evolution. To perform depotassiation, a positive of $+2 \mathrm{~V}$ was applied to extract potassium ions from the potassiated $\mathrm{G}-\mathrm{TiO}_{2} \mathrm{NT}$. The morphological changes are revealed in Fig. 3e-h and Movie S2. With the extraction of potassium ions, the diameter of the potassiated $\mathrm{G}_{-} \mathrm{TiO}_{2} \mathrm{NTs}$ exhibits a discernible shrinkage from 65.6 to $63.5 \mathrm{~nm}$ within $110 \mathrm{~s}$, resulting in a contraction of $3.2 \%$. This implies that the $\mathrm{K}$ ions previously inserted could be reversibly extracted, demonstrating the good reversibility of the $\mathrm{G}^{-\mathrm{TiO}_{2}}$ NTs. For comparison, the potassiation/depotassiation of pure $\mathrm{TiO}_{2}$ NTs were also probed by in situ TEM. During the 


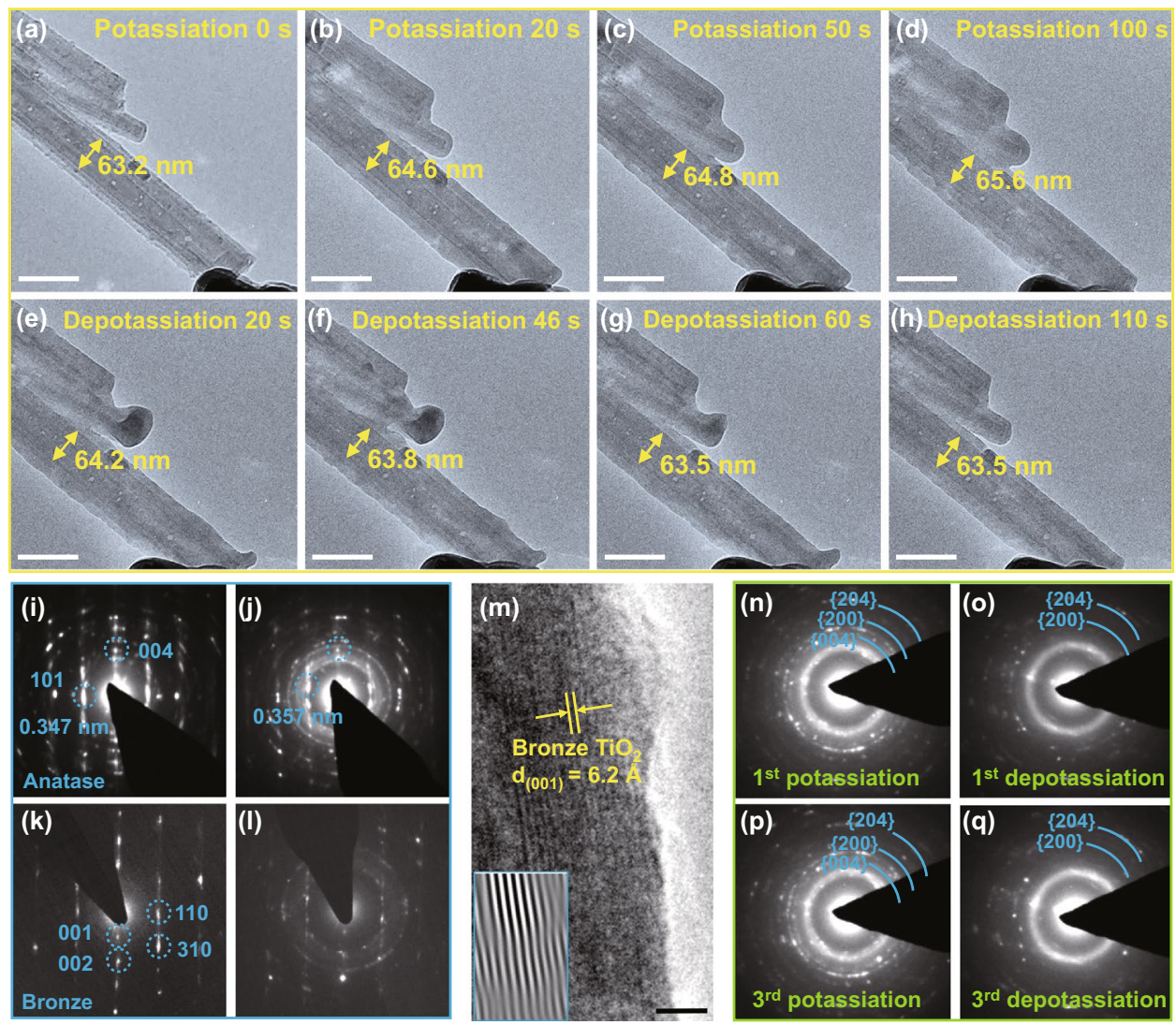

Fig. 3 In situ TEM study of G-TiO ${ }_{2}$ NTs upon potassiation/depotassiation. a-d Time-resolved TEM images showing first electrochemical potassiation process of $\mathrm{G}_{-} \mathrm{TiO}_{2}$ NTs: a A pristine G-TiO ${ }_{2}$ NT. The potassiation was initiated by applying a potential of $-2.0 \mathrm{~V}$ to the NTs. b, $\mathbf{c}$ Small expansions in $\mathrm{G}_{-} \mathrm{TiO}_{2}$ NTs induced by K-ion insertion. $\mathbf{d}$ Fully potassiated $\mathrm{G}_{-} \mathrm{TiO}_{2}$ NTs. $\mathbf{e}-\mathbf{h}$ The first depotassiation process of G-TiO ${ }_{2}$ NTs, with a potential of $+2.0 \mathrm{~V}$ applied to extract $\mathrm{K}$ ions. $\mathbf{i}$ Pristine ED pattern of anatase phase. $\mathbf{j}$ Full potassiation ED pattern of anatase phase. $\mathbf{k}$ Pristine

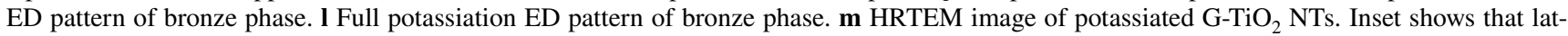
tice fringes of (001) plane of bronze phase were slightly distorted because of the K-ion insertion. $\mathbf{n}-\mathbf{q}$ ED patterns of the first $\mathbf{n}-\mathbf{0}$ and the third $\mathbf{p}, \mathbf{q}$ potassiation/depotassiation products to identify the overall reaction mechanism of G-TiO $\mathrm{NTs}_{2}$ Scale bars: $\mathbf{a}-\mathbf{h} 100 \mathrm{~nm} ; \mathbf{m} 5 \mathrm{~nm}$

first potassiation (Fig. S19a, b, and Movie S3), $\mathrm{TiO}_{2}$ NTs expanded from 110.7 to $114.3 \mathrm{~nm}$ within $10 \mathrm{~s}$, leading to a rapid radial expansion of $\sim 3.25 \%$. Subsequently, the radial expansion of $\mathrm{TiO}_{2}$ NTs increased slightly in next $70 \mathrm{~s}$ and eventually reached $22.6 \%$ (Fig. S19c, d). As for depotassiation, the diameter of pure $\mathrm{TiO}_{2}$ NTs shrinks gradually due to the extraction of K ions (Fig. S19e, f). It is noted that the radial expansion of $\mathrm{G}_{-} \mathrm{TiO}_{2}$ NTs is significantly lower than that of pure $\mathrm{TiO}_{2}$ NTs after the full potassiation. Such conspicuous difference of expansion rates might originate from the mechanical robustness of the graphene coatings [42, 43].

More detailed structural and phase evolution of $\mathrm{G}^{-\mathrm{TiO}_{2}}$ NTs during the first potassiation were pinpointed by electron diffraction (ED) patterns. Two phases of anatase (A) and bronze (B) of the pristine $\mathrm{G}-\mathrm{TiO}_{2}$ NTs can be detected in Fig. 3i, k, respectively. Upon potassiation in the anatase phase (Fig. 3j), the phase structure can be well maintained as evidenced by the remaining (101) and (004) diffraction spots, although the interplanar distance of (101) plane slightly expands to $0.357 \mathrm{~nm}$ induced by the inserted $\mathrm{K}$ ions. Similarly, as with the potassiation in bronze phase (Fig. 31), the parent diffraction spots become weakened. Figure $3 \mathrm{~m}$ displays the corresponding HRTEM image of potassiated bronze phase. It is evident that the lattice fringes of (001) plane are slightly distorted as verified by the ED pattern.

To further identify the overall electrochemical reaction mechanism of $\mathrm{G}_{-} \mathrm{TiO}_{2} \mathrm{NTs}$, cycling performances in anatase phase were investigated. Interestingly, the NTs exhibit multicycle reversible volume expansion/contraction 
in response to the insertion/extraction of $\mathrm{K}$ ions, suggesting the viability of G-TiO ${ }_{2}$ NTs for recyclable KIBs. Accordingly, the ED patterns for the potassiation-depotassiation cycles are acquired in Fig. 3n-q. The first-cycle fully potassiated products are $\mathrm{TiO}_{2}$. This result is in accordance with the above observation. Upon full depotassiation, despite the weakened rings, $\mathrm{TiO}_{2}$ can still be detected. Moreover, the ED pattern of the third-cycle potassiated/depotassiated products also present the identical features to that of the first-cycle depotassiated products. This indicates that $\mathrm{G}_{-} \mathrm{TiO}_{2}$ NTs manifest reliable electrochemical cyclic stability.

Operando XRD was further applied as a powerful technique to provide detailed information on the phase evolution of $\mathrm{G}_{-} \mathrm{TiO}_{2} \mathrm{NT}$ and probe the reaction mechanism during the (de)potassiation process. It was implemented on a customized cell with $\mathrm{G}_{-} \mathrm{TiO}_{2} \mathrm{NTs}$ as the working electrode and $\mathrm{K}$ metal as the counter electrode. The initial cycle of charge-discharge curve between 0.01 and $3 \mathrm{~V}$ and corresponding operando XRD patterns are shown in Fig. 4a, with the related contour map in the range of $2 \theta$ angle plotted in Fig. 4b. In general, the constant signals located at $44.2^{\circ}$ and $46.0^{\circ}$ are related to the $\mathrm{BeO}$ and $\mathrm{Be}$ window, respectively [44]. In the meantime, the dominant peak $\left(\sim 44.8^{\circ}\right)$ of $\mathrm{B}$-phase $\mathrm{TiO}_{2}(60-1)$ shows almost no change in either position or intensity during the entire charge-discharge process, while the A-phase $\mathrm{TiO}_{2}(004)$ at $\sim 38.7^{\circ}$ displays slight shifts toward the low-angle side upon discharge, indicative of the lattice expansion along the A [004] direction upon potassiation, substantiating the occurrence of a K-ion intercalation reaction [45]. In the subsequent charge process, the peak shifts toward high-angle side, implying the dissociation of the intercalated product because of the K-ion extraction. In combination of in situ TEM and operando XRD results during the charge/discharge process, potassium-ion storage mechanism of $\mathrm{G}^{-\mathrm{TiO}_{2}}$ NTs can be described in general by Eqs. 4 and 5:

$\mathrm{K}^{+}$insertion: $\quad \mathrm{TiO}_{2}+x\left(\mathrm{~K}^{+}+\mathrm{e}^{-}\right) \rightarrow \mathrm{K}_{x} \mathrm{TiO}_{2}$

$\mathrm{K}^{+}$extraction: $\quad \mathrm{K}_{x} \mathrm{TiO}_{2} \rightarrow \mathrm{TiO}_{2}+x \mathrm{~K}^{+}+x \mathrm{e}^{-}$

To elucidate the conductivity enhancement of $\mathrm{TiO}_{2}$ NTs after caging graphene $\left(\mathrm{G}-\mathrm{TiO}_{2} \mathrm{NTs}\right)$, the first-principle calculation based on DFT was applied to calculate the density of states (DOS) and partial charge density around Fermi

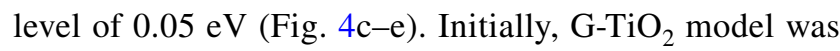
constructed referring to the previous work by using $5 \times 3$ graphene to match $2 \times 2$ anatase $\mathrm{TiO}_{2}(101)$ with an angle of $\sim 110^{\circ}$ (Fig. S20) [21]. DOS calculations indicate that $\mathrm{G}-\mathrm{TiO}_{2}$ composites display metallic nature as compared to the semiconducting anatase $\mathrm{TiO}_{2}$, with the Fermi level shifting up to the conduction band edge of $\mathrm{TiO}_{2}$. It means that the charge transfer from graphene toward $\mathrm{TiO}_{2}$ surface in the $\mathrm{G}_{-} \mathrm{TiO}_{2}$ composites. Partial charge density simulations further show that states around Fermi level are mainly contributed by graphene (Fig. 4e), revealing that the markedly enhanced conductivity of G-TiO ${ }_{2}$ NTs is induced by the involvement of directly grown graphene.

Extensive studies have revealed that the exceptional rate performance of anode materials could be related to their high pseudocapacitance. In this respect, $\mathrm{CV}$ measurements of $\mathrm{G}_{-} \mathrm{TiO}_{2} \mathrm{NTs}$ at various scan rates from 0.1 to $5.0 \mathrm{mV} \mathrm{s}^{-1}$ were performed to interpret this behavior, as displayed in Fig. 4f. Note that similar CV shapes can be attained with a pair of typical redox peaks as the scan rate increases. The charge-storage mechanism can be evaluated according to the relationship between the peak current $i$ and the sweep rate $v: i=a \nu^{b}$ ( $a$ and $b$ are adjustable parameters) [46, 47]. The $b$-value can be determined from the slope of $\log (\nu)-\log (i)$ plot, which lies between 0.5 and 1.0, corresponding to the diffusion-controlled and capacitive-dominant processes, respectively. As with the $\mathrm{G}_{-} \mathrm{TiO}_{2} \mathrm{NT}$ anode, the $b$-value for the anodic peaks is quantified to be 0.84 (Fig. $4 \mathrm{f}$ inset), suggesting that the K-ion intercalation mechanism is dominated by pseudocapacitive ion storage behavior.

In further contexts, the capacitive-controlled $\left(k_{1} v\right)$ and diffusion-controlled $\left(k_{2} v^{1 / 2}\right)$ contributions at given scan rate can be quantitatively determined based on the equation: $i=k_{1} v+k_{2} v^{1 / 2}[48,49] . i$ is the current response associated with the scan rate $(v)$, and $k_{1}$ and $k_{2}$ are constants at a given potential. As displayed in Fig. 4g, a dominant distribution of ca. $79.84 \%$ of the total capacity (the light orange shaded area) at $2 \mathrm{mV} \mathrm{s}^{-1}$ could be quantified to the pseudocapacitive contribution. Such a contribution is calculated to be higher at higher sweep rates, reaching a maximum value of $99.12 \%$ at $5 \mathrm{mV} \mathrm{s}^{-1}$ (Fig. 4h). The enhanced pseudocapacitance is indicative of facile electron delivery and $\mathrm{K}^{+}$ transport, thereby promoting the rate performance of the $\mathrm{G}_{-} \mathrm{TiO}_{2} \mathrm{NT}$ anode toward ultrastable potassium-ion storage. 
(a)
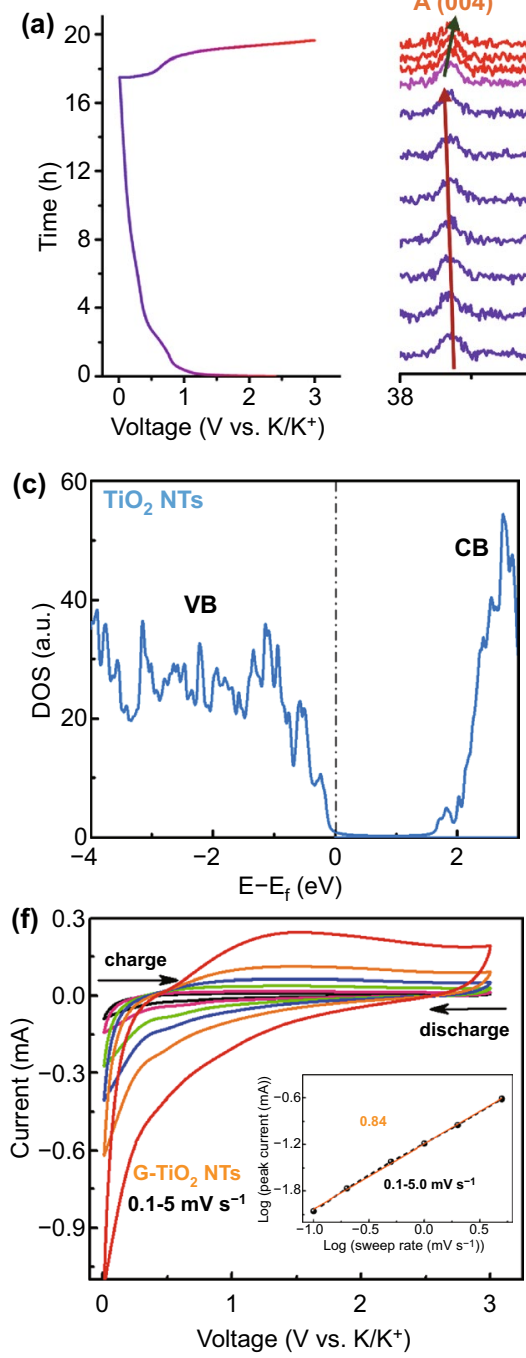

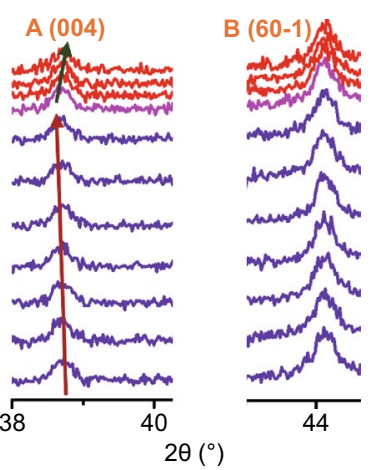

(d)
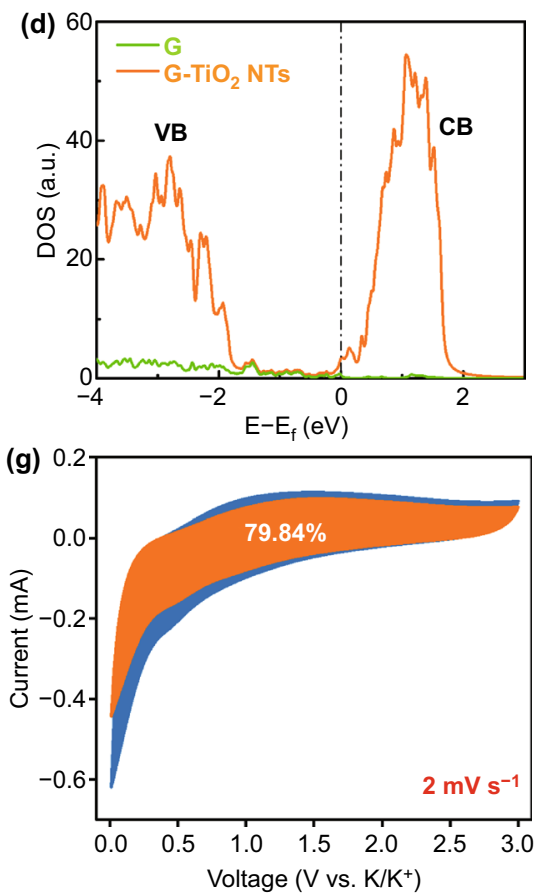
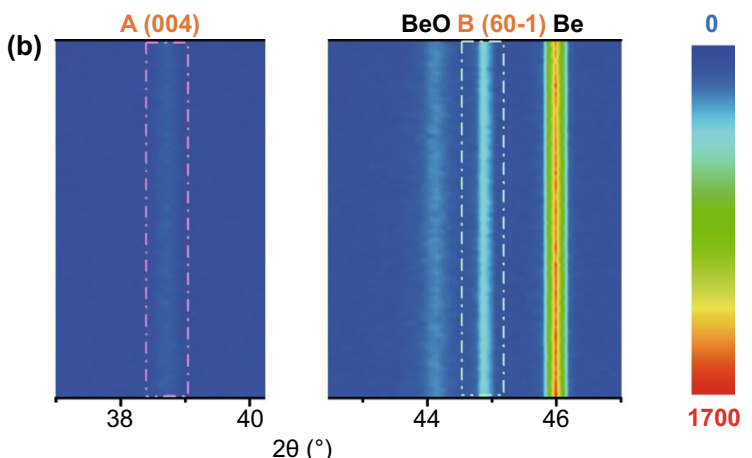

(e)
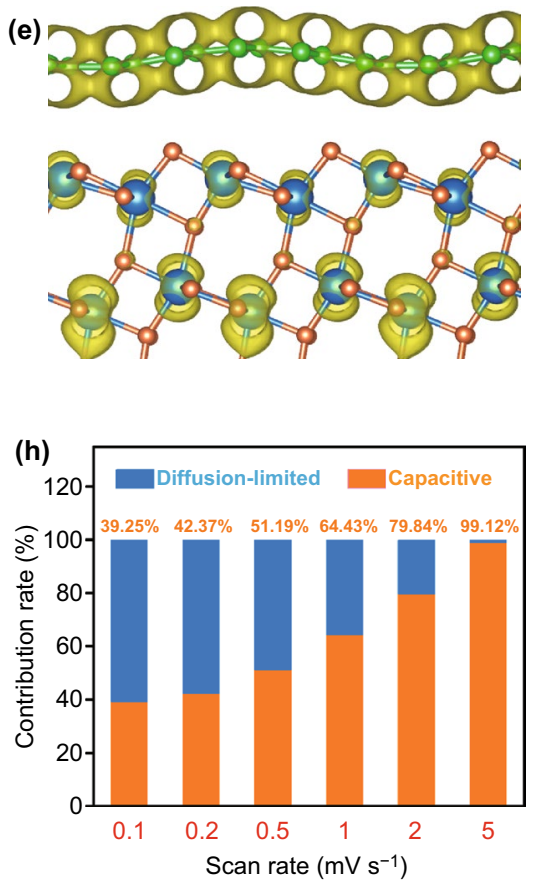

Fig. 4 Operando XRD, first-principle calculations and kinetics analysis of $\mathrm{G}_{-} \mathrm{TiO}_{2} \mathrm{NTs}$ for potassium storage. a The first discharge-charge curve and corresponding operando XRD patterns, showing the signal change of key diffractions with $\mathrm{K}$ metal serving as the counter electrode. b Contour maps for XRD data collected during the first cycle. c, d Calculated density of states (DOSs) for the c) $\mathrm{TiO}_{2}$ and d) $\mathrm{G}_{-} \mathrm{TiO}_{2}$ system. The black dashed line indicates the Fermi level. e Partial charge density around the Fermi level of $0.05 \mathrm{eV}$ by using yellow contour with the isosurface value of $0.0001 \mathrm{eV} / \mathrm{bohr}^{3}$. Ti, $\mathrm{C}$, and $\mathrm{O}$ atoms are in blue, green, and orange color, respectively. $\mathbf{f} \mathrm{CV}$ curves of G-TiO 2 NTs at different scan rates from 0.1 to $5.0 \mathrm{mV} \mathrm{s}^{-1}$. Inset: $b$-value determination from the relationship between the peak currents and the scan rates. $\mathbf{g}$ Separation of the pseudocapacitive contribution (the orange region) for $\mathrm{G}_{-} \mathrm{TiO}_{2} \mathrm{NTs}$ at a CV scan rate of $2 \mathrm{mV} \mathrm{s}^{-1}$. $\mathbf{h}$ Bar chart depicting the percentages of pseudocapacitive contributions at different scan rates from 0.1 to $5 \mathrm{mV} \mathrm{s}^{-1}$

Encouraged by the outstanding potassium storage capability of the $\mathrm{G}_{-} \mathrm{TiO}_{2}$ NTs in half-cells, the KIC full cell is further assembled with the $\mathrm{G}^{-\mathrm{TiO}_{2}}$ NTs as the anode and porous activated carbon (PAC) as the cathode $\left(\mathrm{G}_{-}-\mathrm{TiO}_{2} \mathrm{NTs} / / \mathrm{PAC}\right)$ for proof-of-concept demonstrations, as schematically illustrated in Fig. 5a. During the charge process, K ions partially intercalate into the $\mathrm{TiO}_{2}$ NTs via a Faradaic reaction [50] and partially adsorb on the surface of the electrode/defect sites of the graphene through a pseudocapacitive process, while $\mathrm{PF}_{6}{ }^{-}$adsorbes on the surface of PAC cathode with a high surface area $\left(\sim 1888 \mathrm{~m}^{2} \mathrm{~g}^{-1}\right.$, higher than that of the commercial AC) (Figs. S21 and S22). This process occurs at a voltage range of $1.0-4.0 \mathrm{~V}$ to suppress the decomposition of electrolyte at a low potential and side reactions at an exorbitant voltage, generating high-energy and power outputs. Figure $5 \mathrm{~b}$ exhibits the rate performance of as-constructed KIC full cell, harvesting an energy density of 81.1, 62.5, $47.4,40.7,37.6,33.1$, and $28.9 \mathrm{Wh} \mathrm{kg}^{-1}$ at a current density 
of $0.03,0.05,0.1,0.2,0.5,1.0$, and $2.0 \mathrm{~A} \mathrm{~g}^{-1}$, respectively. The corresponding galvanostatic charge/discharge (GCD) curves are depicted in Fig. 5c, showing typical pseudocapacitive charge-storage features. Furthermore, the G-TiO NTs//PAC KIC device affords a stable capacity retention over 1200 cycles at $1 \mathrm{~A} \mathrm{~g}^{-1}$ (Fig. 5d). As shown in the inset, a "SIEMIS" light-emitting diode pad can be powered by one individual KIC full cell, indicating its potential application as high-energy/high-power energy storage device. Based on the GCD curves, the energy and power densities of the $\mathrm{G}^{-\mathrm{TiO}_{2}}$ (a)

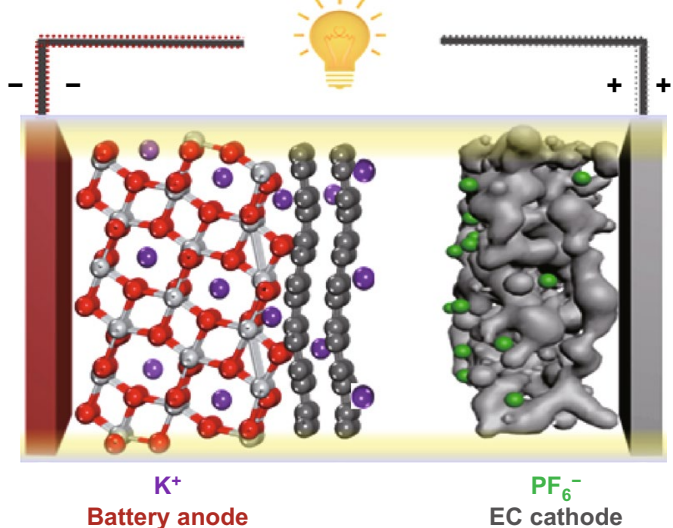

(c)

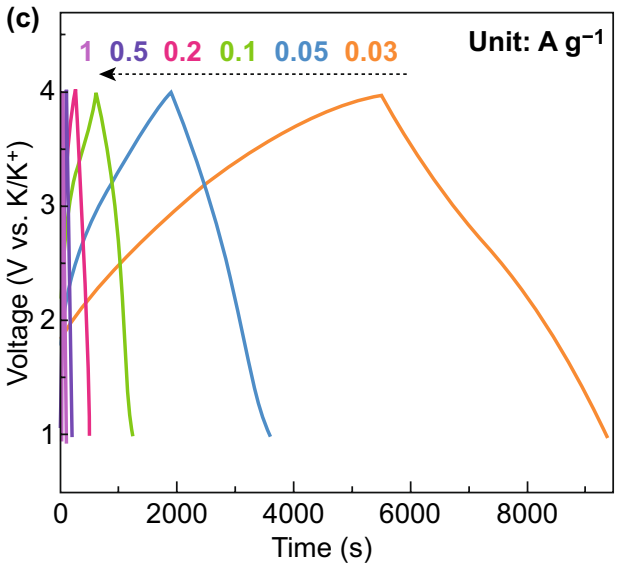

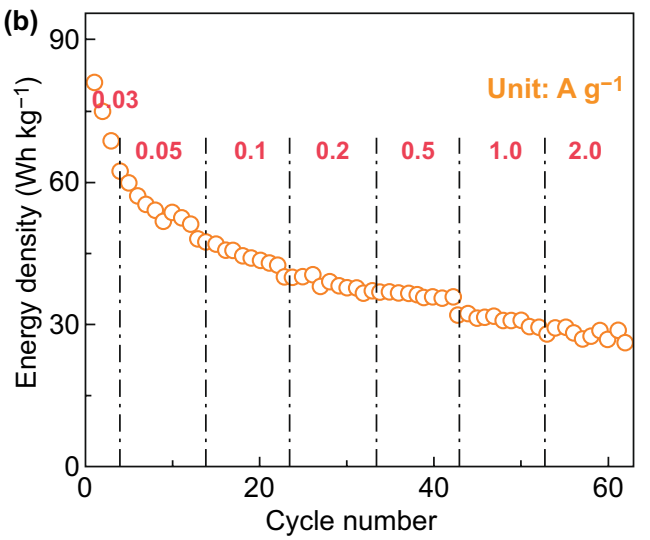

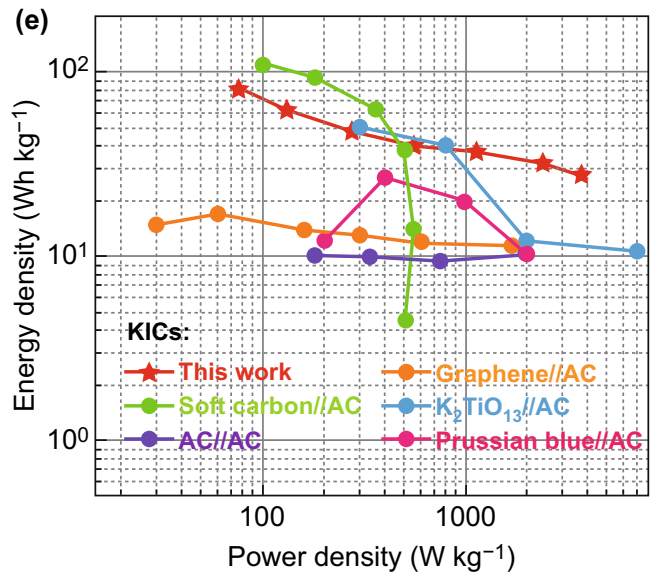

(d)

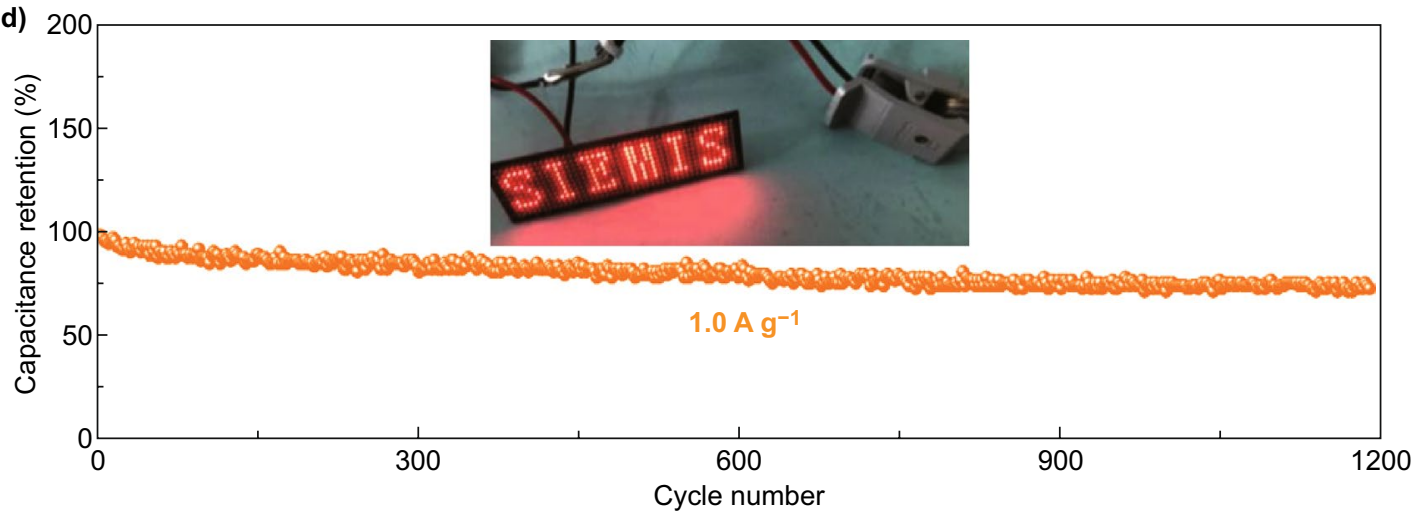

Fig. 5 Electrochemical performance of $\mathrm{G}^{-\mathrm{TiO}_{2}}$ NT-derived KIC full cells. a Schematic illustration of G-TiO $\mathrm{NT}_{2} / \mathrm{PAC} \mathrm{KIC}$ full cell. b Rate performance of KIC devices at current densities from 0.03 to $2.0 \mathrm{~A} \mathrm{~g}^{-1}$. $\mathbf{c}$ Galvanostatic charge/discharge curves of the KIC at different current densities. d Capacitance retention of the KIC at $1 \mathrm{~A} \mathrm{~g}^{-1}$ after 1200 cycles. Inset: a photograph showing a "SIEMIS" LED pad powered by $\mathrm{G}_{-} \mathrm{TiO}_{2} \mathrm{NTs} / / \mathrm{PAC} \mathrm{KIC}$. e Ragone plot of $\mathrm{G}^{-\mathrm{TiO}_{2}}$ NTs//PAC KIC in comparison with other reported KIC systems 
NTs//PAC KIC can be calculated, which delivers an energy density of $81.2 \mathrm{Wh} \mathrm{kg}^{-1}$ at a power density of $75.9 \mathrm{~W} \mathrm{~kg}^{-1}$. It still enables an energy density of $28.1 \mathrm{Wh} \mathrm{kg}^{-1}$ at a power output of $3746.6 \mathrm{~W} \mathrm{~kg}^{-1}$. The Ragone plots in Fig. 5e draw a comparison of the energy/power densities between $\mathrm{G}^{-\mathrm{TiO}_{2}}$ NTs//PAC KIC and the state-of-the-art KICs, manifesting advanced energy/power features of our device as compared to the recently reported systems, such as Graphene//AC [51], $\mathrm{AC} / / \mathrm{AC}[52], \mathrm{K}_{2} \mathrm{TiO}_{13} / / \mathrm{AC}$ [52], Soft carbon//AC [53], and Prussian blue//AC [54].

\section{Conclusions}

In summary, we have developed a direct PECVD strategy to synthesize defective graphene-armored $\mathrm{TiO}_{2}$ NTs in a scalable and economic manner. Such in situ coating of graphene shells endows $\mathrm{TiO}_{2}$ NTs with fast electron/K-ion transport and favorable structural stability, thereby delivering excellent pseudocapacitive potassium storage performance. Thus-derived KIB cells exhibit a high reversible capacity of $332 \mathrm{mAh} \mathrm{g}^{-1}$ at $0.05 \mathrm{~A} \mathrm{~g}^{-1}$ and an unprecedented highrate cyclic stability at $5 \mathrm{~A} \mathrm{~g}^{-1}$ for 3000 cycles with a capacity fading of $0.008 \%$ per cycle. In situ TEM and operando $\mathrm{XRD}$, in combination with first-principle calculations, are employed to systematically probe the potassium storage behavior pertaining to the $\mathrm{G}_{-} \mathrm{TiO}_{2}$ NTs. Furthermore, the KIC full cell is elaborately constructed, which displays a high output voltage of $\sim 3.0 \mathrm{~V}$ and high energy density/power density of $81.2 \mathrm{Wh} \mathrm{kg}^{-1} / 3747 \mathrm{~W} \mathrm{~kg}^{-1}$. Overall, the unique design of in situ graphene-armored coating to allow marginal volume expansion and high-rate ion intercalation of electrodes opens new avenues for developing next-generation KIB systems and beyond targeting real-life applications.

Acknowledgements J.S. Cai, R. Cai, Z.T. Sun, and X.G. Wang contributed equally. This work was financially supported by the National Natural Science Foundation of China (51702225, 11774051, 61574034, 51672007), the National Basic Research Program of China (No. 2016YFA0200103), and the Natural Science Foundation of Jiangsu Province (BK20170336). J.S.C., Z.T.S., X.G.W., N.W., Y.L.S., J.Y.S., and Z.F.L. acknowledge the support from Suzhou Key Laboratory for Advanced Carbon Materials and Wearable Energy Technologies, Suzhou, China.

Open Access This article is licensed under a Creative Commons Attribution 4.0 International License, which permits use, sharing, adaptation, distribution and reproduction in any medium or format, as long as you give appropriate credit to the original author(s) and the source, provide a link to the Creative Commons licence, and indicate if changes were made. The images or other third party material in this article are included in the article's Creative Commons licence, unless indicated otherwise in a credit line to the material. If material is not included in the article's Creative Commons licence and your intended use is not permitted by statutory regulation or exceeds the permitted use, you will need to obtain permission directly from the copyright holder. To view a copy of this licence, visit http://creativecommons.org/licenses/by/4.0/.

Electronic supplementary material The online version of this article (https://doi.org/10.1007/s40820-020-00460-y) contains supplementary material, which is available to authorized users.

\section{References}

1. Y.M. Chiang, Building a better battery. Science 330(6010), 1485-1486 (2010). https://doi.org/10.1126/science.1198591

2. N. Kim, S. Chae, J. Ma, M. Ko, J. Cho, Fast-charging highenergy lithium-ion batteries via implantation of amorphous silicon nanolayer in edge-plane activated graphite anodes. Nat. Commun. 8, 812 (2017). https://doi.org/10.1038/s41467-01700973-y

3. C.Y. Zhao, Y. Cai, K.L. Yin, H.Z. Li, D. Shen et al., Carbonbonded, oxygen-deficient $\mathrm{TiO}_{2}$ nanotubes with hybridized phases for superior Na-ion storage. Chem. Eng. J. 350(15), 201-208 (2018). https://doi.org/10.1016/j.cej.2018.05.194

4. J.T. Xu, Y.H. Dou, Z.X. Wei, J.M. Ma, Y.H. Deng, Y.T. Li, H.K. Liu, S.X. Dou, Recent progress in graphite intercalation compounds for rechargeable metal (Li, Na, K, Al)-ion batteries. Adv. Sci. 4(10), 1700146 (2017). https://doi.org/10.1002/ advs.201700146

5. X. Zhao, F.Y. Gong, Y.D. Zhao, B. Huang, D. Qian, H.E. Wang, W.H. Zhang, Z.J. Yang, Encapsulating NiS nanocrystal into nitrogen-doped carbon framework for high performance sodium/potassium-ion storage. Chem. Eng. J. 392(15), 123675 (2020). https://doi.org/10.1016/j.cej.2019.123675

6. Z.L. Jian, W. Luo, X.L. Ji, Carbon electrodes for K-ion batteries. J. Am. Chem. Soc. 137(36), 11566-11567 (2015). https:// doi.org/10.1021/jacs.5b06809

7. B.J. Yang, J.T. Chen, L.Y. Liu, P.J. Ma, B. Liu, J.W. Lang, Y. Tang, X.B. Yan, 3D nitrogen-doped framework carbon for high-performance potassium ion hybrid capacitor. Energy Storage Mater. 23, 522-529 (2019). https://doi.org/10.1016/j. ensm.2019.04.008

8. J.L. Yang, X. Xiao, W.B. Gong, L. Zhao, G.H. Li et al., Sizeindependent fast ion intercalation in two-dimensional titania nanosheets for alkali-metal-ion batteries. Angew. Chem. Int. Ed. 58(26), 8740-8745 (2019). https://doi.org/10.1002/ anie. 201902478

9. J.F. Ni, S.D. Fu, Y.F. Yuan, L. Ma, Y. Jiang, L. Li, J. Lu, Boosting sodium storage in $\mathrm{TiO}_{2}$ nanotube arrays through surface phosphorylation. Adv. Mater. 30(6), 1704337 (2018). https://doi.org/10.1002/adma.201704337 
10. Z.Y. Le, F. Liu, P. Nie, X.R. Li, X.Y. Liu et al., Pseudocapacitive sodium storage in mesoporous single-crystal-like $\mathrm{TiO}_{2}$-graphene nanocomposite enables high-performance sodium-ion capacitors. ACS Nano 11(3), 2952-2960 (2017). https://doi.org/10.1021/acsnano.6b08332

11. N.N. Wang, C.X. Chu, X. Xu, Y. Du, J. Yang, Z.C. Bai, S.X. Dou, Comprehensive new insights and perspectives into Tibased anodes for next-generation alkaline metal $\left(\mathrm{Na}^{+}, \mathrm{K}^{+}\right)$ion batteries. Adv. Energy Mater. 8(27), 1801888 (2018). https:// doi.org/10.1002/aenm.201801888

12. B. Chen, Y.H. Meng, F.X. Xie, F. He, C.N. He, K. Davey, N.Q. Zhao, S.Z. Qiao, 1D sub-nanotubes with anatase/bronze $\mathrm{TiO}_{2}$ nanocrystal wall for high-rate and long-life sodium-ion batteries. Adv. Mater. 30(46), 1804116 (2018). https://doi. org/10.1002/adma.201804116

13. Y.P. Li, C.H. Yang, F.H. Zheng, Q.C. Pan, Y.Z. Liu et al., Design of $\mathrm{TiO}_{2} \mathrm{eC}$ hierarchical tubular heterostructures for high performance potassium ion batteries. Nano Energy 59, 582-590 (2019). https://doi.org/10.1016/j.nanoen.2019.03.002

14. Y.X. Tang, Y.Y. Zhang, J.Y. Deng, J.Q. Wei, H.L. Tam et al., Mechanical force-driven growth of elongated bending $\mathrm{TiO}_{2}$-based nanotubular materials for ultrafast rechargeable lithium ion batteries. Adv. Mater. 26(35), 6111-6118 (2014). https://doi.org/10.1002/adma.201402000

15. X.G. Wang, Q.C. Li, L. Zhang, Z.L. Hu, L.H. Yu et al., Caging $\mathrm{Nb}_{2} \mathrm{O}_{5}$ nanowires in PECVD-derived graphene capsules toward bendable sodium-ion hybrid supercapacitors. Adv. Mater. 30(26), 1800963 (2018). https://doi.org/10.1002/ adma.201800963

16. H. Kim, J.C. Kim, M. Bianchini, D.H. Seo, J.R. Garcia, G. Ceder, Recent progress and perspective in electrode materials for K-ion batteries. Adv. Energy Mater. 8(9), 1702384 (2018). https://doi.org/10.1002/aenm.201702384

17. G. Kresse, J. Furthmüller, Efficiency of ab initio total energy calculations for metals and semiconductors using a plane-wave basis set. Comput. Mater. Sci. 6(1), 15-50 (1996). https://doi. org/10.1016/0927-0256(96)00008-0

18. P.E. Blöchl, Projector augmented-wave method. Phys. Rev. B 50(24), 17953-17979 (1994). https://doi.org/10.1103/PhysR evB.50.17953

19. J.P. Perdew, K. Burke, M. Ernzerhof, Generalized gradient approximation made simple. Phys. Rev. Lett. 77(18-28), 3865-3868 (1996). https://doi.org/10.1103/PhysRevLet t.77.3865

20. S. Grimme, Semiempirical GGA-type density functional constructed with a long-range dispersion correction. J. Comput. Chem. 27(15), 1787-1799 (2006). https://doi.org/10.1002/ jcc. 20495

21. L. Ferrighi, M. Datteo, G. Fazio, C.D. Valentin, Catalysis under cover: enhanced reactivity at the interface between (doped) graphene and anatase $\mathrm{TiO}_{2}$. J. Am. Chem. Soc. 138(23), 7365-7376 (2016). https://doi.org/10.1021/ jacs.6b02990

22. Y.X. Tang, Y.Y. Zhang, J.Y. Deng, D.P. Qi, W.R. Leow et al., Unravelling the correlation between the aspect ratio of nanotubular structures and their electrochemical performance to achieve high-rate and long-life lithium-ion batteries. Angew. Chem. Int. Ed. 53(49), 13488-13492 (2014). https://doi. org/10.1002/anie.201406719

23. J.L. Li, W. Qin, J.P. Xie, H. Lei, Y.Q. Zhu et al., Sulphurdoped reduced graphene oxide sponges as high-performance free-standing anodes for K-ion storage. Nano Energy 53, 415424 (2018). https://doi.org/10.1016/j.nanoen.2018.08.075

24. H. Ren, R.B. Yu, J. Qi, L.J. Zhang, Q. Jin, D. Wang, Hollow multishelled heterostructured anatase $/ \mathrm{TiO}_{2}(\mathrm{~B})$ with superior rate capability and cycling performance. Adv. Mater. 31(10), 1805754 (2019). https://doi.org/10.1002/adma.201805754

25. J.S. Cai, J.Y. Huang, M.Z. Ge, J. Iocozzia, Z.Q. Lin, K.Q. Zhang, Y.K. Lai, Immobilization of Pt nanoparticles via rapid and reusable electropolymerization of dopamine on $\mathrm{TiO}_{2}$ nanotube arrays for reversible SERS substrates and nonenzymatic glucose sensors. Small 13(19), 1604240 (2017). https:// doi.org/10.1002/smll.201604240

26. J.Y. Sun, Y.B. Chen, M.K. Priydarshi, T. Gao, X.J. Song, Y.F. Zhang, Z.F. Liu, Graphene glass from direct CVD routes: production and applications. Adv. Mater. 28(46), 10333 (2016). https://doi.org/10.1002/adma.201602247

27. J.Y. Sun, T. Gao, X.J. Song, Y.F. Zhao, Y.W. Lin et al., Direct growth of high-quality graphene on high-к dielectric $\mathrm{SrTiO}_{3}$ substrates. J. Am. Chem. Soc. 136(18), 6574-6577 (2014). https://doi.org/10.1021/ja5022602

28. Y.K. Wang, R.F. Zhang, J. Chen, H. Wu, S.Y. Lu et al., Enhancing catalytic activity of titanium oxide in lithium-sulfur batteries by band engineering. Adv. Energy Mater. 9(24), 1900953 (2019). https://doi.org/10.1002/aenm.201900953

29. T.Y. Lei, Y.M. Xie, X.F. Wang, S.Y. Miao, J. Xiong, C.L. Yan, $\mathrm{TiO}_{2}$ feather duster as effective polysulfides restrictor for enhanced electrochemical kinetics in lithium-sulfur batteries. Small 13(37), 1701013 (2017). https://doi.org/10.1002/ smll.201701013

30. Y. Cai, H.-E. Wang, X. Zhao, F. Huang, C. Wang et al., Walnut-like porous core/shell $\mathrm{TiO}_{2}$ with hybridized phases enabling fast and stable lithium storage. ACS Appl. Mater. Interfaces 9(12), 10652-10663 (2017). https://doi.org/10.1021/ acsami.6b16498

31. H.-E. Wang, K.L. Yin, N. Qin, X. Zhao, F.-J. Xia et al., Oxygen-deficient titanium dioxide as a functional host for lithiumsulfur batteries. J. Mater. Chem. A 7, 10346-10353 (2019). https://doi.org/10.1039/C9TA01598A

32. F. Giordano, A. Abate, J.P.C. Baena, M. Saliba, T. Matsui et al., Enhanced electronic properties in mesoporous $\mathrm{TiO}_{2}$ via lithium doping for high-efficiency perovskite solar cells. Nat. Commun. 7, 10379 (2016). https://doi.org/10.1038/ncomm s10379

33. J. Zheng, Y. Yang, X.L. Fan, G.B. Ji, X. Ji et al., Extremely stable antimony-carbon composite anodes for potassium-ion batteries. Energy Environ. Sci. 12, 615-623 (2019). https:// doi.org/10.1039/C8EE02836B

34. J.Y. Shin, J.H. Joo, D. Samuelis, J. Maier, Oxygen-deficient $\mathrm{TiO}_{2}-\delta$ nanoparticles via hydrogen reduction for high rate capability lithium batteries. Chem. Mater. 24(3), 543-551 (2012). https://doi.org/10.1021/cm2031009 
35. P.H. Li, W. Wang, S. Gong, F. Lv, H.X. Huang et al., Hydrogenated $\mathrm{Na}_{2} \mathrm{Ti}_{3} \mathrm{O}_{7}$ epitaxially grown on flexible $\mathrm{N}$-doped carbon sponge for potassium-ion batteries. ACS Appl. Mater. Interfaces 10(44), 37974-37980 (2018). https://doi. org/10.1021/acsami.8b11354

36. J. Han, M.W. Xu, Y.B. Niu, G.N. Li, M.Q. Wang, Y. Zhang, M. Jia, C.M. Li, Exploration of $\mathrm{K}_{2} \mathrm{Ti}_{8} \mathrm{O}_{17}$ as an anode material for potassium-ion batteries. Chem. Commun. 52, 11274-11276 (2016). https://doi.org/10.1039/C6CC05102B

37. B.B. Tian, W. Tang, K. Leng, Z.X. Chen, S.J.R. Tan et al., Phase transformations in $\mathrm{TiS}_{2}$ during $\mathrm{K}$ intercalation. ACS Energy Lett. 2(8), 1835-1840 (2017). https://doi.org/10.1021/ acsenergylett.7b00529

38. P.C. Lian, Y.F. Dong, Z.S. Wu, S.H. Zheng, X.H. Wang et al., Alkalized $\mathrm{Ti}_{3} \mathrm{C}_{2}$ MXene nanoribbons with expanded interlayer spacing for high-capacity sodium and potassium ion batteries. Nano Energy 40, 1-8 (2017). https://doi.org/10.1016/j.nanoe n.2017.08.002

39. Y.F. Dong, Z.S. Wu, S.H. Zheng, X.H. Wang, J.Q. Qin, S. Wang, X.Y. Shi, X.H. Bao, $\mathrm{Ti}_{3} \mathrm{C}_{2}$ MXene-derived sodium/ potassium titanate nanoribbons for high-performance sodium/ potassium ion batteries with enhanced capacities. ACS Nano 11(15), 4792-4800 (2017). https://doi.org/10.1021/acsna no. $7 \mathrm{~b} 01165$

40. G. Fang, Z. Wu, J. Zhou, C. Zhu, X. Cao et al., Observation of pseudocapacitive effect and fast ion diffusion in bimetallic sulfides as an advanced sodium-ion battery anode. Adv. Energy Mater. 8(19), 1703155 (2018). https://doi.org/10.1002/ aenm.201703155

41. X.Y. Tao, J.G. Wang, C. Liu, H.T. Wang, H.B. Yao et al., Balancing surface adsorption and diffusion of lithium-polysulfides on nonconductive oxides for lithium-sulfur battery design. Nat. Commun. 7, 11203 (2016). https://doi.org/10.1038/ ncomms 11203

42. J. Sun, H.W. Lee, M. Pasta, H.T. Yuan, G.Y. Zheng, Y.M. Sun, Y.Z. Li, Y. Cui, A phosphorene-graphene hybrid material as a high-capacity anode for sodium-ion batteries. Nat. Nanotechnol. 10, 980-985 (2015). https://doi.org/10.1038/nnano .2015 .194

43. Q.M. Su, G.H. Du, J. Zhang, Y.J. Zhong, B.S. Xu, Y.H. Yang, S.M. Neupane, K. Kadel, W.Z. Li, Visualizing individual nitrogen dopants in monolayer graphene. Science 333(6045), 999-1003 (2011). https://doi.org/10.1126/science.1208759

44. M.T. Xia, T.T. Liu, N. Peng, R.T. Zheng, X. Cheng, H.J. Zhu, H.X. Yu, M. Shui, J. Shu, Lab-scale in situ X-ray diffraction technique for different battery systems: designs, applications, and perspectives. Small Methods 3(7), 1900119 (2019). https ://doi.org/10.1002/smtd.201900119
45. H. Wei, E.F. Rodriguez, A.F. Hollenkamp, A.I. Bhatt, D.H. Chen, R.A. Caruso, High reversible pseudocapacity in mesoporous yolk-shell anatase $\mathrm{TiO}_{2} / \mathrm{TiO}_{2}(\mathrm{~B})$ microspheres used as anodes for Li-ion batteries. Adv. Funct. Mater. 27(46), 1703270 (2017). https://doi.org/10.1002/adfm.201703270

46. V. Augustyn, J. Come, M.A. Lowe, J.W. Kim, P.L. Taberna, S.H. Tolbert, H.D. Abruña, P. Simon, B. Dunn, High-rate electrochemical energy storage through $\mathrm{Li}^{+}$intercalation pseudocapacitance. Nat. Mater. 12, 518-522 (2013). https://doi. org/10.1038/nmat3601

47. Z.Y. Zhang, M.L. Li, Y. Gao, Z.X. Wei, M.N. Zhang et al., Fast potassium storage in hierarchical $\mathrm{Ca}_{0.5} \mathrm{Ti}_{2}\left(\mathrm{PO}_{4}\right)_{3} @ \mathrm{C}$ microspheres enabling high-performance potassium-ion capacitors. Adv. Funct. Mater. 28(36), 1802684 (2018). https ://doi.org/10.1002/adfm.201802684

48. J. Wang, J. Polleux, J. Lim, B. Dunn, Pseudocapacitive contributions to electrochemical energy storage in $\mathrm{TiO}_{2}$ (anatase) nanoparticles. J. Phys. Chem. C 111(40), 14925-14931 (2007). https://doi.org/10.1021/jp074464w

49. J.T. Chen, B.J. Yang, H.X. Li, P.J. Ma, J.W. Lang, X.B. Yan, Candle soot: onion-like carbon, an advanced anode material for a potassium-ion hybrid capacitor. J. Mater. Chem. A 7, 9247-9252 (2019). https://doi.org/10.1039/C9TA01653H

50. J.Y. Hwang, S.T. Myung, Y.K. Sun, Recent progress in rechargeable potassium batteries. Adv. Funct. Mater. 28(43), 1802938 (2018). https://doi.org/10.1002/adfm.201802938

51. A. Comte, Y. Reynier, C. Vincens, C. Leys, P. Azaïs, First prototypes of hybrid potassium-ion capacitor (KIC): an innovative, cost-effective energy storage technology for transportation applications. J. Power Sour. 363(30), 34-43 (2017). https ://doi.org/10.1016/j.jpowsour.2017.07.005

52. Z.Q. Xu, M.Q. Wu, Z. Chen, C. Chen, J. Yang, T.T. Feng, E. Paek, D. Mitlin, Direct structure-performance comparison of all-carbon potassium and sodium ion capacitors. Adv. Sci. 6(12), 1802272 (2019). https://doi.org/10.1002/advs.20180 2272

53. L. Fan, K. Lin, J. Wang, R. Ma, B. Lu, A nonaqueous potassium-based battery-supercapacitor hybrid device. Adv. Mater. 30(20), 1800804 (2018). https://doi.org/10.1002/adma.20180 0804

54. J.T. Chen, B.J. Yang, H.J. Hou, H.X. Li, L. Liu, L. Zhang, X.B. Yan, Potassium-ion batteries: disordered, large interlayer spacing, and oxygen-rich carbon nanosheets for potassium ion hybrid capacitor. Adv. Energy Mater. 9(19), 1803894 (2019). https://doi.org/10.1002/aenm.201970069 